\title{
Knowledge and Attitude of Radiology Technologists Towards Cardiopulmonary Resuscitation
}

\author{
Hamid Behroozi ${ }^{1, *}$; Masoumeh Alboghbeish ${ }^{2}$; Ali Khalafi ${ }^{2}$; Ahmad Azizi ${ }^{3}$; Marzieh \\ Tahmasebi ${ }^{1}$; Shahriar Aghasi ${ }^{1}$ \\ ${ }^{1}$ Department of Radiologic Technology, School of Paramedical, Ahvaz Jundishapur University of Medical Sciences, Ahvaz, IR Iran \\ ${ }_{2}^{2}$ Department of Anesthesiology, School of Paramedical, Ahvaz Jundishapur University of Medical Sciences, Ahvaz, IR Iran \\ ${ }^{3}$ Department of Health Information Technology, School of Paramedical, Ahvaz Jundishapur University of Medical Sciences, Ahvaz, IR Iran \\ ${ }^{*}$ Corresponding author: Hamid Behroozi, Department of Radiologic Technology, School of Paramedical, Ahvaz Jundishapur University of Medical Sciences, Ahvaz, IR Iran. \\ Tel: +98-6113738317, Fax: +98-6113738330, E-mail: Hamidbeh2001@yahoo.co.uk
}

Received: February 17, 2015; Revised: April 7, 2015; Accepted: April 2, 2015

\begin{abstract}
Background: The number of casualties and critically ill patients referred to radiology departments increased during the past decade, which caused the risk of cardiac arrest in radiology departments to increase considerably.

Objectives: The current study aimed to evaluate the knowledge and attitude of radiology technologists regarding Cardiopulmonary Resuscitation (CPR).

Patients and Methods: After approval a cross sectional study was designed. Ninety five radiology technologists (male and female) were selected in four tertiary referral hospitals in Ahvaz, Iran. Accordingly, 87 radiologic technologists of which agreed to participate in the study. The researchers developed a questionnaire. The questionnaire consisted of three distinct sections including demographic data, attitude, and technical knowledge questions. Reliability of the technical knowledge questions were evaluated using Cronbach's alpha (76\%). Data collection was performed using interview method.

Results: Of the total 87 questionnaires, one was incomplete. None of the participants had attended a training program since employment. The average scores of attitude towards CPR and technical knowledge were $80 \pm 8.9$ and $8.8 \pm 2.3$, respectively. A correlation was observed between age and work experience $(r=0.866, P \leq 0.0001)$, age and technical knowledge $(r=0.380, P \leq 0.0001)$, work experience and technical knowledge $(r=0.317, P=0.003)$, and attitude and technical knowledge $(r=0.397, P \leq 0.0001)$. Also a correlation was observed between work experience and attitude $(r=0.385, P \leq 0.0001)$. No significant difference was observed between male and female subjects' technical knowledge $(\mathrm{P} \geq 0.05)$ and attitude $(\mathrm{P} \geq 0.05)$.

Conclusions: It can be concluded that, although the attitude of participants towards CPR was positive in general, their technical knowledge was poor.This finding should urge decision-makers to consider delivering in-service training courses to radiology technologists considering the increasing number of casualties and critically ill patients referred to radiology departments.
\end{abstract}

Keywords: Electric Countershock; Heart Arrest; Cardiopulmonary Resuscitation

\section{Background}

According to the World Health Organization (WHO), 1.2 million people are killed in road accidents each year and as many as 50 million people are injured worldwide. These figures will increase by about $65 \%$ over the next 20 years unless there is a new commitment to prevention (1). It is reported that Iran is the fifth country in the world regarding the number of road accidents (2).

of the injured individuals, some may have a critical condition due to severe trauma while others may have incurred superficial injuries (3-5). In general, almost all road accident injured individuals need to be taken care of in hospitals regardless of the severity of injuries (6). Patients with multiple trauma injuries are normally admitted to emergency departments of the hospitals. As the evidence shows, it is hard to imagine contemporary medicine without using X-rays as diagnostic tools in road accident casualties (7-9).
According to guidelines, some advanced imaging systems including digital radiography systems, and Computed Tomography (CT) are installed in emergency departments to meet the needs of critically ill patients in this respect (10). On the contrary, some of the casualties need to be transferred to imaging departments, for complementary radiological procedures, located far from the emergency department. These casualties are normally accompanied by a skilled nurse and a general practitioner during transfer to the imaging department to monitor the patient's condition and to deal with potential critical events. This discipline is disregarded when a collective event happens due to a lack of sufficiently trained and competent personnel to manage such circumstances $(11,12)$. In addition to emergency department casualties some of the critically ill patients of intensive care units also need to be transferred to imaging departments for

Copyright (C) 2015, Ahvaz Jundishapur University of Medical Sciences. This is an open-access article distributed under the terms of the Creative Commons Attribution-NonCommercial 4.0 International License (http://creativecommons.org/licenses/by-nc/4.0/) which permits copy and redistribute the material just in noncommercial usages, provided the original work is properly cited. 
follow-up procedures (5). In addition, there exists the risk of cardiac arrest in the patients who are administered contrast media for imaging procedures in imaging departments (13-15). They show that the issue of Cardiopulmonary Resuscitation (CPR) in the imaging department is a critical one.

Jundishapur University of Medical Sciences supervises 28 hospitals, out of which four hospitals are tertiary referral hospitals. Critically ill patients and casualties are referred to tertiary teaching hospitals. The evidence shows that bystander CPR can double or triple survival rates after cardiac arrest (16-18). However, according to the guidelines, CPR teams in hospitals should be called when necessary. During the past few years the vital signs of some casualty patients deteriorate on the imaging system table and finally expire before the resuscitation team has arrived. Under such circumstances, the radiology technologist is the first individual who could perform CPR promptly in the absence of the radiologist.

According to educational programs, radiology technologists pass a theoretical course titled patient care in imaging department. It contains basic life support and first aid modules.

\section{Objectives}

The current study aimed to evaluate the knowledge and attitude of radiology technologists in teaching hospitals.

\section{Patients and Methods}

After study approval (study code U-92221, ethics code 1392.357), a cross sectional study was designed in 2013 and the researchers developed a questionnaire. The questionnaire consisted of three distinct sections: 1) Demographic data: consisted of three questions (age, gender, work experience, see appendix); 2) Attitude towards CPR which comprised 23 questions in general and subdivided into five sections, which were: general attitude toward CPR; positive attitude towards CPR protocol; negative attitude toward CPR protocol; attitude towards CPR practice; and finally, the attitude of radiology technologists towards CPR specifically. Attitude of participants was evaluated using a 5-point Likert scale (from $1=$ strongly disagree to $5=$ strongly agree for positive questions and from $1=$ strongly agree to 5 = strongly disagree for negative questions). Validity of this section was assessed by experts from psychiatry department; 3) Seventeen multiple choice questions were designed by the colleagues from anesthesiology department to assess technical knowledge regarding CPR. The reliability of the third section questions (technical knowledge section) was evaluated using Cronbach's alpha (76\%). Score of one was assigned to every correct answer. Total score of every participant was recorded.

Accordingly, 95 radiology technologists were selected in the tertiary teaching hospitals. An invitation letter was sent to the head of imaging department of the teaching hospitals. Finally, 87 radiology technologists who consent- ed to participate in the study were registered. An appointment for interview was sent to every technologist (19).

Interview was performed in conference room in each imaging department. Before the interview, necessary information was presented. First, the technical questions were answered by every subject in 15 minutes. Second, interviewer completed the attitude section by presenting a question and the answer obtained. The obtained data were transferred to SPSS version 15.

\subsection{Statistical Analysis}

Kolmogorove-Smirnove (K-S) test was used to assess data normal distribution. The t-test (independent samples) was used to test differences between groups (male and female subjects). Pearson correlation test was used to test association between the variables such as attitude score and technical knowledge score. A P value $<0.05$ was used as cut-off point for significance. SPSS version 15 was used for statistical analysis.

\section{Results}

The technical knowledge and attitude of radiology technologists regarding CPR were evaluated. The questionnaire consisted of demographic data, attitude, and technical knowledge questions. Table 1 shows the demographic characteristics of respondents.

Table 2 shows that the mean of attitude score and the mean of male and female subjects' attitude score are the same. Table 2 also shows that score of the technical knowledge of female subjects is superior compared with those of the total average and male subjects. Regarding the general attitude towards CPR, $44 \%(n=38)$ of respondents feared to injure the patients. The same proportion (44\%) of respondents also stated that they were not able to perform CPR. Nevertheless, $41 \%(n=36)$ of respondents stated that they were competent to work with the resuscitation teams.

\begin{tabular}{lc}
\hline Table 1. Demographic Characteristics of Respondents \\
\hline Variable & Mean, $\mathbf{y}$ \\
\hline Overall Age & $33 \pm 5.9$ \\
\hline Female age & $33 \pm 6.6$ \\
Male age & $33 \pm 5.7$ \\
\hline Overall work experience & $9 \pm 5.7$ \\
Female work experience & $8 \pm 6.5$ \\
Male work experience & $9 \pm 5.3$ \\
\hline
\end{tabular}

\begin{tabular}{lc}
\hline \multicolumn{2}{l}{ Table 2. Mean Scores of Technical Knowledge and Attitude } \\
\hline Variable & Mean \\
\hline Overall attitude & $80 \pm 8.9$ \\
\hline Overall knowledge & $8.8 \pm 2.3$ \\
\hline Females attitude & $79 \pm 10$ \\
\hline Females knowledge & $9 \pm 2.2$ \\
\hline Males attitude & $81 \pm 7.4$ \\
\hline Males knowledge & $8.6 \pm 2.2$ \\
\hline
\end{tabular}


In terms of positive attitude towards resuscitation guidelines, $56 \%(n=49)$ of the respondents stated that resuscitation guidelines were useful as educational tools. Regarding negative attitudes towards resuscitation, 39\% $(n=34)$ stated that implementation of resuscitation guidelines were too difficult for them. Pertaining to attitude towards implementation of resuscitation, only $34 \%(n=29)$ had studied the current guidelines of resuscitation. Finally, regarding attitudes towards the role of radiographic experts, 80\% ( $\mathrm{n}=$ 70) of the respondents stated that the first person arriving to the resuscitation scene should perform CPR.

Table 3 shows a correlation between age and work experience (years of working), work experience and attitude, and age and technical knowledge score. Also a correlation was observed between work experience and technical knowledge and finally between attitude and technical knowledge. No significant difference was observed between male and female subjects in technical knowledge scores. Also no significant difference was observed between male and female subjects regarding attitude.

Table 4 shows that only $35 \%$ of the participants answered question nine correctly which asked "What would be your immediate action if you confirmed somebody was not responding to you even after shaking and shouting at him?" The rate of correct answers to question 16, which asked "What is the rate of chest compression in adult and children in CPR?" was similar to that of question nine. $80 \%$ of respondents answered question three correctly. This question asked "Which pulse do you check when you find someone unresponsive?"

\begin{tabular}{lcc}
\hline Table 3. Results of Correlation Test & & \\
\hline Correlation & r & P \\
\hline Age and work experience & 0.866 & $<0.0001$ \\
Work experience and attitude & 0.385 & $<0.0001$ \\
Age and technical knowledge & 0.380 & $<0.0001$ \\
Work experience and technical knowledge & 0.317 & 0.003 \\
\hline Attitude and technical knowledge & 0.392 & $<0.0001$ \\
\hline
\end{tabular}

\begin{tabular}{lc}
\hline \multicolumn{2}{l}{ Table 4. Rate of Correct Answers to the Knowledge Questions } \\
\hline Question No. & Rate of Correct Response \\
\hline 1. & $49(57)$ \\
\hline 2. & $57(66)$ \\
\hline 3. & $69(80)$ \\
\hline 4. & $50(54)$ \\
\hline 5. & $53(61)$ \\
\hline 6. & $36(42)$ \\
\hline 7. & $63(73)$ \\
\hline 8. & $66(76)$ \\
\hline 9. & $30(35)$ \\
\hline 10. & $62(71)$ \\
\hline 11. & $50(57)$ \\
\hline 12. & $43(50)$ \\
\hline 13. & $68(78)$ \\
\hline 14. & $60(69)$ \\
\hline 15. & $47(54)$ \\
\hline 16. & $30(35)$ \\
\hline 17. & $40(47)$ \\
\hline a & \\
\hline
\end{tabular}

\footnotetext{
a Data are presented as No. (\%).
}

\section{Discussion}

The technical knowledge and attitude of radiology technologists regarding CPR in imaging departments of tertiary teaching hospitals were evaluated. Due to the lack of similar studies, general comparisons were performed. The results of current study showed that radiology technologists participating in the study generally had a positive attitude towards CPR ( $80 \pm$ out of 115), and a correlation was also observed between attitude towards CPR and technical knowledge. On the contrary, the technical knowledge of participants was poor (average $8.8 \pm 2.3$ of 17), which was in contrast with the findings of Parnell et al. (20) who showed that students with a positive attitude toward CPR and first aid acquired a higher technical knowledge score than those with a negative attitude. But it was in line with the findings of Aaberg et al. (16) and Giri et al (21).

In terms of work experience, a correlation was observed between the years of work experience and technical knowledge $(r=0.317)$, which was in agreement with the findings of Boddu et al. (22) where none of the respondents had attended an educational or training course regarding CPR since employment. It suggests that being in the work environment could increase the technical knowledge of participants effectively. Surprisingly, Tapping and Culverwell (23) found no significant difference between the likelihood of the correct answer and the radiologists' grade (years of experience) for the similar conditions (radiology department).

There was a correlation $(r=0.385)$ between work experience and attitude, which suggests that being in the environment may alter the attitude of participants. Nevertheless, only $56 \%(n=48)$ of participants felt that the role of radiographers regarding $C P R$ performance is changing positively. A correlation $(r=0.866)$ was also observed between age and experience, which confirms the correlation between work experience and technical knowledge $(24,25)$. Therefore, according to the study findings, aging increases experience and experience increases the level of technical knowledge.

It was also revealed that $59 \%(n=51)$ of subjects felt incompetent to perform CPR correctly, which was in line with the findings of Mpotos et al. (26) who found that $69 \%$ of the subjects felt incompetent to perform CPR correctly. On the contrary, $80 \%(n=70)$ of the subjects stated that the first person arriving to the resuscitation scene should perform CPR. It means that the majority of radiology technologists had a reasonable perception of CPR importance.

The rate of correct answers to the technical knowledge questions was $35 \%-80 \%$. Therefore none of the subjects answered all questions correctly. But the majority of respondents could answer the easier questions. Since none of the participants had attended in-service training since employment, it is assumed that educational programs of public media such as TV and radio are beneficial as a re- 
minder in this regard. Close contact with the emergency department staff should be considered too.

Although the subjects had positive attitude towards CPR, their technical knowledge was insufficient. This finding should urge decision makers to consider in-service education and training of radiology technologists considering the growing number of casualties amongst critically ill patients referred to radiology departments.

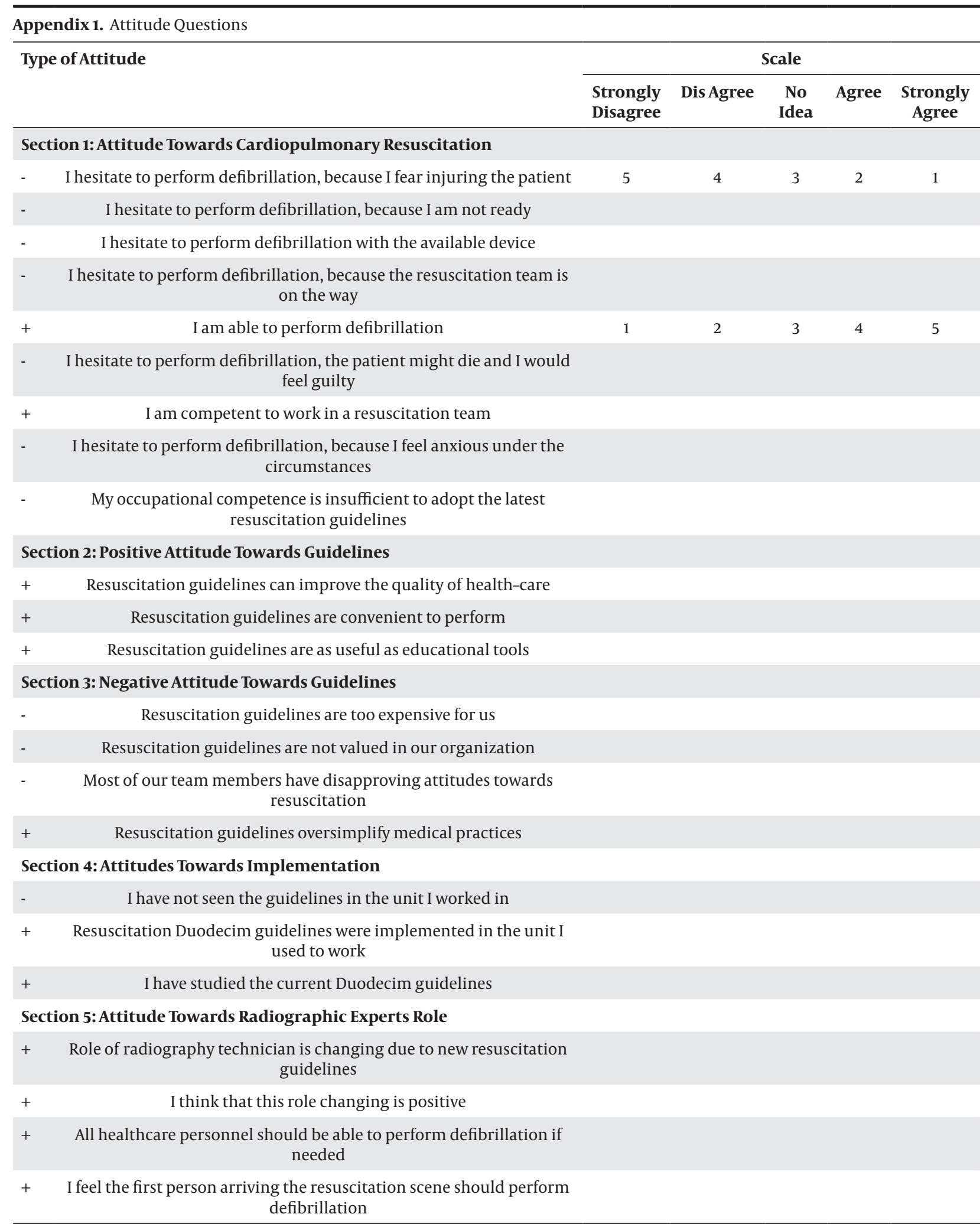


Appendix 2. Technical Knowledge Questions

\section{1- What is the Abbreviation of "BLS"?}

a. Best Life Support

b. Basic Life Support

c. Basic Lung Support

d. Basic Life Services

2- When you find someone unresponsive in radiology unit, what would be your first action? (Note: You are alone there)

a. Open airway

b. Start chest compression

c. Look for safety

d. Give two breathings

3-When you find someone unresponsive which pulse do you check?

$$
\begin{aligned}
& \text { a. Radial } \\
& \text { b. Brachial } \\
& \text { c. Ulnar } \\
& \text { d. Carotid }
\end{aligned}
$$

4- If you confirm somebody is not responding to you even after shaking and shouting at him, what will be your immediate action?

\section{a. Start CPR}

b. Activate EMS

c. Put him in recovery position

d. Observe

5- Where is the location for chest compression?

a. Left side of the chest

b. Right side of the chest

c. Mid chest

d. Xiphisternum

6- Where is the location for chest compression in infants?

a. One finger breadth below the nipple line

b. One finger breadth above the nipple line

c. At the intermammary line

d. At Xiphisternum

7- If you do not want to give mouth-to-mouth CPR, the following can be done EXCEPT

a. Mouth-mask ventilation and chest compression

b. Chest compression only

c. Bag mask ventilation which chest compression

d. No CPR

8- Rate of chest compression in adults and Children during CPR

a. $100 / \mathrm{min}$

b. $120 / \mathrm{min}$

c. $80 / \mathrm{min}$

d. $70 / \mathrm{min}$

9- Ratio of CPR in adult is

a. $15: 2$

b. 5:1

c. $30: 2$

d. 15:1

10- Depth of compression in adults during CPR

$$
\begin{aligned}
& \text { a. } 1_{1 / 2}-2 \text { inches } \\
& \text { b. } 21 / 2-3 \text { inches } \\
& \text { c. } 1-1 \frac{1}{2} \text { inches } \\
& \text { d. } 1 / 2-1 \text { inch }
\end{aligned}
$$

11- Which surface is suitable for performing CPR?

$$
\text { a. Hard surface }
$$

b. Soft surface c. On the bed

d. Wherever you are dominant

12. What is the appropriate maneuver used for opening airway?

a. Head tilt-chin lift

b. Head flexion-chin lift

c. Head tilt-chin down

d. Head flexion-chin down

13. What is the appropriate approach to ensure effective breathing

a. Asking the patient for symptoms of dyspnea

b. Closing face to the patient's mouth and nose, looking at the chest movement

c. Attention to skin color, dilated pupils and pulse rate

d. Start CPR in not responsive patients

14. If a patient in radiology department suddenly suffers bleeding, what will be your immediate action?

a. Placing the patient in a position with feet above the body

b. using tourniquet above bleeding location

c. Putting a compression bandage on the bleeding location

d. Call emergency unit

15. What is the appropriate position for patient with sever nausea and vomiting?

$$
\begin{aligned}
& \text { a. Prone } \\
& \text { b. semi sitting } \\
& \text { c. sitting } \\
& \text { d. lateral }
\end{aligned}
$$

16. What is the sign and symptom of internal bleeding?

a. Flashing, confusion, tachycardia

b. Paleness, LOC decrease, tachycardia

c. Cyanosis, confusion, bradycardia

d. Tiredness, bradypenea, coughing

17. What is the appropriate place for starting CPR?

\author{
a. Hard \\ b. Soft \\ c. On the bed \\ d. Each plane that one is dominant when CPR
}

\section{Acknowledgements}

This research was fully supported by Deputy of Research of Jundisahpur University of Medical Sciences (Grant Code U- 92221). The authors using this opportunity to express their gratitude to Dr Sakey and his colleagues. The authors also express their warm thanks to all colleagues in tertiary teaching hospital hospitals ( Golestan, Imam,Razi and Abuzar) who facilitated data collection.

\section{References}

1. Peden M. World report on road traffic injury prevention.Geneva: World Health Organization; 2004.

2. Naghavi M, Shahraz S, Bhalla K, Jafari N, Pourmalek F, Bartels D, et al. Adverse health outcomes of road traffic injuries in Iran after rapid motorization. Arch Iran Med. 2009;12(3):284-94.

3. Saadat S, Mafi M, Sharif-Alhoseini M. Population based estimates of non-fatal injuries in the capital of Iran. BMC Public Health. 2011;11:608.

4. Sass AC, Stang A. Population-based incidences of non-fatal injuries - results of the German-wide telephone survey 2004. BMC Public Health. 2013;13:376.

5. Olajumoke TO, Oyebamiji EO, Afolayan JM, Adekunle M. Trauma admissions into the intensive care unit and outcome of care in 
a tertiary health facility. Nigerian journal of medicine: journal of the National Association of Resident Doctors of Nigeria. 2013;23(4):296-301.

6. Tuckel P, Milczarski W, Maisel R. Pedestrian injuries due to collisions with bicycles in New York and California. J Safety Res. 2014;51:7-13.

7. Hall EJ, Brenner DJ. Cancer risks from diagnostic radiology. $\mathrm{Br} J$ Radiol. 2008;81(965):362-78.

8. Adiotomre A, Chopra A, Kirwadi A, Kotnis N. Results from the first year as a major trauma radiology unit in the UK. Clin Radiol. 2014;69(8):812-21.

9. Whiley SP, Alves H, Grace S. Full-body x-ray imaging to facilitate triage: a potential aid in high-volume emergency departments. Emerg Med Int. 2013;2013:437078.

10. Lee J, Kirschner J, Pawa S, Wiener DE, Newman DH, Shah K. Computed tomography use in the adult emergency department of an academic urban hospital from 2001 to 2007. Ann Emerg Med. 2010;56(6):591-6.

11. Nekooei Moghaddam M, Saeed S, Khanjani N, Arab M. Nurses' requirements for relief and casualty support in disasters: a qualitative study. Nurs Midwifery Stud. 2014;3(1):e9939.

12. Hogan DE, Brown T. Utility of vital signs in mass casualty-disaster triage. West J Emerg Med. 2014;15(7):732-5.

13. Palmiere C, Reggiani Bonetti L. Risk factors in fatal cases of anaphylaxis due to contrast media: a forensic evaluation. Int Arch Allergy Immunol. 2014;164(4):280-8.

14. Kalaiselvan V, Sharma S, Singh GN. Adverse reactions to contrast media: an analysis of spontaneous reports in the database of the pharmacovigilance programme of India. Drug Saf. 2014;37(9):703-10.

15. Saito M, Abe M, Furukawa T, Yagi M, Koike Y, Wakasugi Y, et al. Examination of Patients Suspected as Having Hypersensitivity to Iodinated Contrast Media with Leukocyte Migration Test. Biological and Pharmaceutical Bulletin. 2014;37(11):1750-7.

16. Aaberg AM, Larsen CE, Rasmussen BS, Hansen CM, Larsen JM. Basic life support knowledge, self-reported skills and fears in Danish high school students and effect of a single 45-min training session run by junior doctors; a prospective cohort study. Scand J Trauma Resusc Emerg Med. 2014;22:24.

17. Kitamura T, Morita S, Kiyohara K, Nishiyama C, Kajino K, Sakai T, et al. Trends in survival among elderly patients with out-of-hospital cardiac arrest: a prospective, population-based observation from 1999 to 2011 in Osaka. Resuscitation. 2014;85(11):1432-8.

18. Kallestedt ML, Berglund A, Herlitz J, Leppert J, Enlund M. The impact of CPR and AED training on healthcare professionals' selfperceived attitudes to performing resuscitation. Scand J Trauma Resusc Emerg Med. 2012;20:26.

19. Toklu HZ, Uysal MK. The knowledge and attitude of the Turkish community pharmacists toward pharmacovigilance in the Kadikoy district of Istanbul. Pharm World Sci. 2008;30(5):556-62.

20. Parnell MM, Pearson J, Galletly DC, Larsen PD. Knowledge of and attitudes towards resuscitation in New Zealand high-school students. Emerg Med J. 2006;23(12):899-902.

21. Giri PA, Bangal VB, Phalke DB. Knowledge and attitude of medical undergraduate, interns and postgraduate students in India towards emergency contraception. NAm J Med Sci. 2013;5(1):37-40.

22. Boddu S, Prathigudupu RS, Somuri AV, Lingamaneni KP, Rao P, Kuchimanchi PK. Evaluation of knowledge and experience among oral and maxillofacial surgeons about cardiopulmonary resuscitation. J Contemp Dent Pract. 2012;13(6):878-81.

23. Tapping CR, Culverwell AD. Are radiologists able to manage serious anaphylactic reactions and cardiopulmonary arrest? Br J Radiol. 2009;82(982):793-9.

24. McCulloch P, Mishra A, Handa A, Dale T, Hirst G, Catchpole K. The effects of aviation-style non-technical skills training on technical performance and outcome in the operating theatre. Qual Saf Health Care. 2009;18(2):109-15.

25. Flin R, Maran N. Identifying and training non-technical skills for teams in acute medicine. Qual Saf Health Care. 2004;13 Suppl 1:180-4.

26. Mpotos N, Vekeman E, Monsieurs K, Derese A, Valcke M. Knowledge and willingness to teach cardiopulmonary resuscitation: a survey amongst 4273 teachers. Resuscitation. 2013;84(4):496-500. 